\title{
Violent Comic Books and Perceptions of Ambiguous Provocation Situations
}

\author{
Steven J. Kirsh \\ Paul V. Olczak
}

\author{
Department of Psychology \\ State University of New York-Geneseo
}

\begin{abstract}
This study investigated the effects of reading very violent versus mildly violent comic books on the interpretation of ambiguous provocation situations, independent of trait hostility. 119 introductory psychology students read either a violent comic book, Curse of the Spawn, or a mildly violent comic book, Archie \& Friends. After reading the comic books, participants read six short stories in which a child caused a negative event to happen to another child, but the intent of the peer causing this negative event was ambiguous. After each story, participants were asked a series of questions about the harmdoer's intent, potential retaliation toward the harmdoer, and about the harmdoer's emotional state. Responses were coded in terms of amount of negative and violent content. Results indicate that those male participants reading the violent comic books responded more negatively on the ambiguous provocation story questions than male participants reading the mildly violent comic books. For females, responding was primarily governed by trait hostility. These data suggest that hostile attributional bias may be influenced by gender, trait hostility, and exposure to violent media.
\end{abstract}

Over the past two decades, voluminous research has focused on media influences (e.g., television, video games) on aggression. These studies consistently find that exposure to violent themes in media is significantly related to aggressive behavior and thoughts (Anderson, 1997, Berkowitz, 1984, Cesarone, 1998). An additional, yet understudied, source of media violence to which individuals are frequently exposed is comic books. Recent statistics show that approximately $\$ 400$ million in comic books (at around $\$ 2$ per comic) are sold annually, with a top selling comic producing around 150,000 copies in advance orders per month (Antonucci, 1998). Historically, the target audience for comic books has been 10-

Requests for reprints should be sent to Steven Kirsh, Department of Psychology, SUNY-Geneseo, Geneseo, NY14454. E-mail: kirsh@geneseo.edu 
to 14-year-old boys, however, recent estimates suggest that comic book readers vary greatly in age. Antonucci reported that as many as $25 \%$ of comic books sales may come from individuals over age 40.

In the 1950s, concern that violence in comic books might increase aggression in children (Wertham, 1954) led to the development of a Comics Code Authority, a self-censoring agency for comic book content developed and enforced by the producers of comic books (Savage, 1990). However, the overwhelming majority of comic books available today still contain violent themes (see Diamond Comic Distributors's, 1999, webpage for a list of the top 100 selling comic books by month), and many comic books are laden with graphic gore and sexual themes. In fact, finding a comic book without any acts of aggression is nearly impossible. Even comic books that are meant to be funny (e.g., The Simpsons, Rug Rat Adventures) contain acts of aggression.

Although television, video games, and comic books all contain portrayals of violence, the nature of the depiction of the violence differs. Comic books, unlike television and video games, do not provide a continuous story in which all of the action relevant to the storyline is displayed. In comic books, the storyline is told in partially connected frames. Thus, continuity between frames must be inferred by the reader. For instance, in one frame of a comic book a lone hero was shown brandishing a sword in an attack arc. Then, the next frame of the comic book depicted a warrior lying on the ground with the hero standing over him. Although the actual duel to the death was not shown, the reader must infer that the hero killed the warrior with his sword. This type of disconnected presentation of information forces the readers to engage their imagination (McCloud, 1993). As the previous example illustrates, when reading violent comic books, individuals are not simply witnessing depictions of aggressive behavior, they are in fact becoming active participants in the creation of the aggression-laden storyline (McCloud, 1993).

In addition, unlike the presentation of information on television or in video games, when reading comic books, individuals can self-regulate the intake of information by adjusting the speed at which they read. Individuals can spend as much time as they like reading dialogue and viewing a picture. The ability to selfpace the reading of a comic book may afford a detailed encoding of the stimulus material. Given that individuals read comic books at a comfortable, self-guided pace, and that they become actively engaged in the storyline of comic books, the potential influence of this form of media seems great (Potenza, Verhoeff, \& Weiss, 1996). However, to date, there are very few studies that have assessed either the benefits or drawbacks of comic books (Potenza, Verhoeff, \& Weiss, 1996).

The few studies that have assessed the impact of comic books have yielded some interesting findings. For instance, comic books have been shown to 
increase children's understanding of physical disabilities (Kokaska, 1984) and have been used to promote sex education (Gordon \& Conant, 1974) and AIDS education (Gillmore et al., 1997). Although positive effects of reading comic books have been identified, additional research suggests that exposure to violent themes in comic books may have a negative impact on an individual's functioning. For instance, Brand (1969) found a link between aggressive themes in comic books and aggressive feelings in adolescence. However, no research has focused on the effects of exposure to violent themes in comic books on adults' perceptions of aggression. Thus, given the increasing age of comic book readers, it becomes necessary to assess the impact of violent comic books beyond childhood and adolescence.

One explanation for the link between reading violent comic books and aggression comes from the literature on social information-processing in aggressive children. Dodge (1980) contended that aggressive children act aggressively, in part, due to a hostile attributional bias.

A hostile attributional bias occurs when an individual infers hostile intent to the actions of another, even though the intent of that individual is unclear. Thus, when exposed to a frustrating social stimulus (e.g., being hit in the back with a ball), a hostile attributional bias may result in cue distortion, which leads aggressive individuals to interpret the stimulus as an aggressive cue and thus respond aggressively (Dodge \& Frame, 1982).

Research on hostile attributional bias has focused primarily on aggressive children (Dodge, 1980; Dodge \& Frame, 1982). Consistently, Dodge and his colleagues have found that when harm occurs under ambiguous circumstances (i.e., the intent of the harmdoer is unclear), aggressive children ascribe hostile intent to the harmdoer. Dodge contended that socialization experiences lead to the formation of a hostile attributional bias. For instance, frequently aggressive children (i.e., children who display a hostile attributional bias) are raised by parents who display little warmth and rely on physical punishment as a source of discipline (Parke \& Slaby, 1983). Recently, Kirsh (1998) demonstrated that, for third- and fourth-grade children, a hostile attributional bias follows violent video game play. Thus, in addition to familial experiences, some forms of media appear to lead to the development of a short-term hostile attributional bias.

Similar to the case of violent video games, it is possible that exposure to violent comic books may contribute to the development of a hostile attributional bias and thus become a risk factor for aggressive behavior. Thus, one purpose of the present research is to investigate the impact of violence in comic books on the appraisal of ambiguous situations, that is, situations that could be interpreted as having occurred under hostile or benign intent. 
Research on television has demonstrated that pre-existing anger appears to increase the negative influence of violent television (Dubow \& Miller, 1996). Furthermore, in a study on adults, Epps and Kendall (1995) found a significant relationship between trait hostility and hostile attributional bias. Given these findings, participants' trait tendency to respond with hostility and anger was measured prior to the experimental condition. In order to assess a comic book induced hostile attributional bias, independent of trait hostility, we then statistically removed the influence of trait hostility on the dependent variable.

To test the proposition that reading violent comic books leads to a hostile attributional bias, participants read either a very violent comic book (i.e., Curse of the Spawn) or a relatively nonviolent comic book (i.e., Archie \& Friends). After reading the comic book, participants interpreted a series of ambiguous provocation stories, that is, stories in which harm could have occurred under hostile or benign intent. After each story, participants were asked a series of questions: two questions about the harmdoer's intent, two questions about potential retaliation and punishment, and two questions about the harmdoer's emotional state. We hypothesized that individuals exposed to the very violent comic book would show evidence of a hostile attributional bias and therefore ascribe more hostile intent to the harmdoer than adults exposed to the relatively nonviolent comic book. Given that a hostile attributional bias is thought to influence retaliatory aggression (Dodge, 1980), we hypothesized that participants reading the very violent comic book would suggest more retaliation and expect more punishment than participants reading the relatively nonviolent comic book. Similarly, based on the social cognitive contention that individuals with a hostile attributional bias will seek to justify their actions, it was hypothesized that participants reading the very violent comic book would ascribe a more negative emotional state to the harmdoer than the other participants.

Although hostile attributional bias has been primarily studied in males (Epps $\&$ Kendall, 1995), additional researchers have challenged the contention that the experience and expression of anger (Brody, 1993) and hostile attributional bias are gender specific (Slaby \& Guerra, 1988). Furthermore, there is some evidence that aggressive girls display a hostile attributional bias similar to that of aggressive boys during both middle childhood and adolescence (Crick, 1995; Steinberg \& Dodge, 1983). Given the lack of research in the area, no genderspecific predictions are offered. It should be noted that no consistent gender differences have been found with respect to the influence of violent television on boys'and girls'aggression (Dubow \& Miller, 1996).

In summary, the primary purpose of the present research was to investigate the socializing influence of comic books on aggressive thought. This research 
will help determine whether reading violent comic books influences social information-processing independent of trait hostility.

\section{METHOD}

\section{Participants}

The participants were 119 introductory psychology students (74\% female) at a mid-sized college in Western New York state. The distribution of males and females in this study approximated the gender distribution at the college.

\section{Procedure}

At the beginning of the semester, participants filled out the Buss-Durkee Hostility Inventory (BDHI; Buss \& Durkee, 1957) to assess their trait level of hostility. Approximately 6-10 weeks later, these participants were recruited to participate in the comic book study. Research assistants, blind to the participants' trait hostility scores, randomly assigned participants to one of two conditions: very violent and mildly violent comic books. Participants in the very violent condition read comic books with a high degree of violence and aggressive themes. Examples of violence and aggressive themes found in the highly aggressive comic book used in the present study include fighting, killing, showing dead bodies, threatening words or behavior, destruction of property, and forcible restraint. Participants in the mildly violent condition read a relatively nonviolent comic book. Examples of aggression shown in the relatively nonviolent comic book include, pushing, name calling, and tripping.

To help reduce the demand characteristics of the study, participants were told that the researchers were developing measures for two separate studies on children and that their input was needed to help develop appropriate measures. Specifically, participants were told that one of the studies deals with children's perceptions of comic books and that the other study assesses children's perceptions of things that happen to them at home and at school. First, participants read their assigned comic book and completed the comic book rating task. Then, as a separate assessment, participants read and answered questions about a series of ambiguous provocation stories. For this task, participants were asked to respond to the questions as they thought a 10-year-old would respond. The ambiguous provocation stories task is a projective test. Projective tests are based on the projective hypothesis that states that a person's response to an ambiguous or vague stimulus is a reflection (i.e., projection) of his or her own 
needs and feelings. That is, the person, in giving meaning to an ambiguous stimulus, "projects" onto that stimulus his or her own needs, feelings, strivings, and thought processes (Frank, 1939). The research that has accumulated on the projective approach over the years has found it to be predictive of significant aspects of personality (i.e., aggression), in certain situations (Feshbach \& Weiner, 1986; Janda, 1998). Thus, participants' responses should reflect their current state of mind, with regard to hostile/nonhostile perceptions. At the same time, this line of questioning should maintain the pretense that the researchers were developing experimental measures for children. Finally, participants were asked a series of questions about their experience with comic books using a Comic Book History Form.

\section{Materials}

Comic Books. The comic books used in this study are Curse of the Spawn (McElroy, 1998) and Archie \& Friends (DeCesare \& Goldberg, 1998). Curse of the Spawn (Issues $12 \& 18$ ) relays the continuing saga of Jason Wynn and Jessica Priest as they attempt to fight evil with their combat skill, intellect, and ruthless tactics. This comic book was used in the very violent condition of the experiment. Approximately $85 \%$ of the panels in Curse of the Spawn contain violent acts and/or aggressive themes. Archie \& Friends follows the humorous (although occasionally hostile or aggressive) adventures of Archie, Veronica, Betty, Jughead, and others during high school. Each Archie \& Friends comic book consists of four or five independent stories. This comic book was used in the mildly violent condition of the experiment. Approximately $7 \%$ of the panels in Archie \& Friends contain violent acts and/or hostile or aggressive themes

To help equate the two experimental conditions on reading, related boredom, and fatigue, participants in the very violent condition read two full Curse of the Spawn comics, whereas participants in the mildly violent condition read approximately one and one-quarter of Archie \& Friends comic books. Both conditions involved approximately 20 minutes of reading. Regardless of the comic book condition, all participants read completed story lines.

Comic Book History Form. Participants were asked to provide a list of comic books they have read in the last 6 months and how often they read comic books.

Comic Book Rating Form. To ensure that the comic books were perceived as very violent or mildly violent, participants rated the violence level in their 
assigned comic book. In addition, to reduce demand characteristics and maintain the ruse that we needed comic book ratings for a future study, participants rated the humor, interest level, and overall likeability of their assigned comic book. All questions involved 7-point Likert-type scales.

Predispositional Anger. Participants' propensity to respond to a variety of situations with anger was assessed using the BDHI. According to Geen (1998), the BDHI has been the most popular of all the personality measures that have been used in research on aggression. The BDHI consists of 75 true-false questions made up of seven subscales and a total hostility score. Studies using the total score on the BDHI as a global measure of hostility have found that high scorers retaliated sooner and delivered significantly more and stronger shocks to another person than low scorers in an experimental aggression situation (Knott, 1970) and that they perceived significantly more violence than low scorers in the binocular rivalry situation developed by Toch and Schulte (Petzel \& Michaels, 1973).

Ambiguous Provocation Stories Task. For this assessment, participants read six stories in which a child causes a negative event to happen to another child but the intent of the harmdoer is unclear. For instance, in one story a child gets hit in the back with a ball; in a second story a child gets tripped into a puddle; and in a third story milk spills onto a child. The stories are written such that it is unclear as to whether the child was hit/tripped/spilled-upon by accident or on purpose. After each story, participants were asked six questions: two questions about the harmdoer's intent; two questions about potential retaliation and punishment toward the harmdoer; and two questions about the harmdoer's emotional state. Responses were written down by participants and then coded in terms of amount of negative and aggressive content. Composite variables were formed by combining like questions. Specifically, the two intent-related questions were combined to form an intent variable; the two punishment-related questions were combined to form a retaliation variable; and the two emotionrelated questions were combined to form an emotion variable. For each composite variable (intent, retaliation, emotion), responses were summed across all six stories (possible range: $0-12$ ). Alpha scores for the 12 responses within each composite variable ranged from .64 to .66. The relatively low internal consistency for the composite variables suggests that the results should be interpreted with caution. 


\section{RESULTS}

\section{Preliminary Analyses}

Comic Book History. Very few participants in this study had read comic books recently. In fact, only $9 \%$ had read a comic book (violent or nonviolent) in the last 6 months. Thus, prior exposure to comic books does not appear to be a factor in this study.

Comic Book Ratings. A series of 2 (Comic Book) x 2 (Gender) analyses of variance (ANOVA) was conducted. For liking, there were no significant main effects for comic book or gender. However, the Comic Book x Gender interaction effect was significant, $F(1,115)=25.2, p<.001$. Post-hoc LSD tests indicated that females liked Archie \& Friends significantly more than males reading Archie \& Friends and females reading Curse of the Spawn. In contrast, males liked the very violent comic book more than females reading the very violent comic book and more than males reading the mildly violent comic book. The ANOVA for interest revealed only a significant Comic Book $x$ Gender interaction effect, $F(1,115)=20.1, p<.001$. Post hoc LSD tests indicated that females were interested in Archie \& Friends significantly more than males reading Archie \& Friends and females reading Curse of the Spawn. In contrast, males were more interested in the very violent comic book than females were in reading the very violent comic book and than males were in reading the mildly violent comic book. For humor, there was a significant main effect for comic book, $F(1,115)=20.1, p<.001$, in which Archie \& Friends was rated as significantly more humorous than Curse of the Spawn. However, a significant interaction effect, $F(1,115)=13.8, p=.003$, was also found. Post-hoc LSD tests indicated that females reading Archie \& Friends rated the comic book as significantly more funny than any other group. The ANOVA for aggression yielded a significant main effect for comic book. Results indicated that Curse of the Spawn was rated as significantly more violent than Archie \& Friends. See Table 1 for means and standard deviations of the comic book ratings as a function of gender and comic book type.

Trait Hostility. Analyses were conducted to assess the relation between trait hostility and scores on the composite variables. For all participants, results indicated significant Pearson product-moment correlations between trait hostility and intent $(r=.43, p<.01)$, Retaliation $(r=.44, p<.01)$, and Emotion $(r=.48$, $p<.01)$. For each variable, negative responding increased the more trait hostility 
an individual possessed. Thus, in order to assess the influence of comic book type and gender on perceptions of social situations independent of trait hostility, trait hostility was entered as a covariate in subsequent analyses.

\section{TABLE 1}

Mean and Standard Deviations (in Parentheses) of Comic Book Ratings as a Function of Gender of Respondent and Comic Book

\begin{tabular}{|c|c|c|c|c|c|c|c|c|}
\hline \multirow{4}{*}{ Question } & \multicolumn{8}{|c|}{ Comic Book } \\
\hline & \multicolumn{4}{|c|}{ Archie } & \multicolumn{4}{|c|}{ Curse of the Spawn } \\
\hline & \multicolumn{2}{|c|}{ Male $^{\mathrm{a}}$} & \multicolumn{2}{|c|}{ Female $^{\mathrm{b}}$} & \multicolumn{2}{|c|}{ Male $^{\mathrm{c}}$} & \multicolumn{2}{|c|}{ Female $^{\mathrm{d}}$} \\
\hline & & & & $\overline{S D}$ & $M$ & $S D$ & $M$ & $S D$ \\
\hline $\begin{array}{l}\text { How much did you like } \\
\text { your comic book? }\end{array}$ & $2.9^{\mathrm{x}}$ & 1.3 & $4.2^{\mathrm{y}}$ & 1.4 & $4.2^{\mathrm{y}}$ & 1.8 & $2.2^{\mathrm{x}}$ & 1.6 \\
\hline $\begin{array}{l}\text { How interesting did you } \\
\text { find your comic book? }\end{array}$ & $2.8^{\mathrm{x}}$ & 1.4 & $4.2^{\mathrm{y}}$ & 1.1 & $4.6^{y}$ & 1.4 & $3.3^{x}$ & 1.7 \\
\hline $\begin{array}{l}\text { How humorous did you } \\
\text { find your comic book? }\end{array}$ & $2.9^{\mathrm{y}}$ & 1.3 & $3.7^{\mathrm{z}}$ & 1.3 & $2.4^{x y}$ & 1.5 & $1.8^{\mathrm{x}}$ & 1.0 \\
\hline $\begin{array}{l}\text { How aggressive did you } \\
\text { find your comic book? }\end{array}$ & $1.7^{\mathrm{x}}$ & 0.8 & $2.4^{\mathrm{x}}$ & 1.5 & $6.8^{y}$ & 0.4 & $6.8^{y}$ & 0.4 \\
\hline
\end{tabular}

Note. Means in the same row that do not share superscripts differ at $p<.05$ by LSD tests. ${ }^{\mathrm{a}} n=13 .{ }^{\mathrm{b}} n=43 .{ }^{\mathrm{c}} n=18 .{ }^{\mathrm{d}} n=45$.

\section{Primary Analyses}

In order to test the contention that violent comic books influence the processing of social information, a series of 2 (Comic Book) x 2 (Gender) analyses of covariance (ANCOVAs) was conducted. For intent, the main effects for comic book and gender were both nonsignificant. However, the Comic Book x Gender interaction effect was significant, $F(1,114)=6.0, p=.016$. Post-hoc LSD tests indicated that males reading the very violent comic book reported more hostile intent than males reading the mildly violent comic book. For females, there were no differences in reported intent between those reading the very violent and mildly violent comic books. The ANCOVA for retaliation yielded a significant main effect for comic book, $F(1,114)=4.9, p=.028$. Participants reading Curse of the Spawn suggested more aggressive retaliation than participants reading Archie \& Friends. The main effect for gender and the interaction effect were both nonsignificant. Results for emotion indicated a significant comic book main effect, $F(1,114)=8.2, p=.005$. Participants reading Curse of the Spawninferred 
a more negative emotional state to the harmdoer than participants reading Archie \& Friends. However, a significant Comic Book x Gender interaction effect, $F(1,114)=7.6, p=.007$ was also found. Post-hoc LSD tests indicated that males reading the very violent comic book were more negative than males reading the mildly violent comic book. Furthermore, males reading Curse of the Spawn gave more negative answers than females reading Curse of the Spawn and Archie \& Friends. No other significant differences were evident. Table 2 presents the estimated means and standard errors for the composite variables, taking into consideration the covariate.

\section{TABLE 2}

Estimated Means and Standard Errors (in Parentheses) of Intent, Retaliation, and Emotion as a Function of Gender and Comic Book Type

\begin{tabular}{|c|c|c|c|c|c|c|}
\hline \multirow[t]{2}{*}{ Comic Book } & \multicolumn{2}{|c|}{ Intent } & \multicolumn{2}{|c|}{ Retaliation } & \multicolumn{2}{|c|}{ Emotion } \\
\hline & $M$ & $S D$ & $M$ & $S D$ & $M$ & $S D$ \\
\hline \multicolumn{7}{|c|}{ Archie \& Friends } \\
\hline Male $^{\mathrm{a}}$ & $4.4^{\mathrm{x}}$ & .62 & 6.5 & .61 & $4.0^{\mathrm{x}}$ & .59 \\
\hline Female $^{\mathrm{b}}$ & $5.6^{x y}$ & .35 & 6.9 & .34 & $5.1^{\mathrm{x}}$ & .33 \\
\hline Total & 5.0 & .35 & $6.7^{x}$ & .35 & 4.6 & .34 \\
\hline \multicolumn{7}{|c|}{ Curse of the Spawn } \\
\hline Male & $6.5^{\mathrm{y}}$ & .53 & 8.1 & .52 & $6.5^{y}$ & .50 \\
\hline Female $^{\mathrm{d}}$ & $5.3^{x y}$ & .34 & 7.3 & .33 & $5.2^{\mathrm{x}}$ & .32 \\
\hline Total & 5.9 & .31 & $7.7^{y}$ & .31 & 5.8 & .30 \\
\hline
\end{tabular}

Note. Comparisons are by columns only. Means in the same column that do not share superscripts differ at $p<.05$ by LSD (Intent, Emotion) or $F$ test (Retaliation). For retaliation, only the main effect for comic book yielded statistically significant differences. Means in the same row that do not share superscripts differ at $p<.05$ by LSD tests. ${ }^{\mathrm{a}} n=13 .{ }^{\mathrm{b}} n=43 .{ }^{\mathrm{c}} n=18 .{ }^{\mathrm{d}} n=45$.

\section{DISCUSSION}

\section{Preliminary Analyses}

Comic Book Ratings. Importantly, participants rated the aggressiveness of the comic books as expected. This finding provides validity for the a priori rating of violence assigned to the experimental stimuli used in each condition. Interestingly, significant gender differences were generally evident in the perception of the comic books. Females liked and were more interested in Archie 
$\&$ Friends than were males. In contrast, males liked and were more interested in Curse of the Spawn than were females. These findings are consistent with Hirschman's (1987) finding that females prefer to watch television shows involving relational issues (Archie \& Friends is replete with relational storylines), and males prefer television shows that allow for escapism (a quality found in Curse of the Spawn). Furthermore, given that the vast majority of comic books today contain violence and that the percentage of comic book readers beyond early adolescence has been increasing (Antonucci, 1998), it is not surprising that males in their late teens and early twenties (i.e., participants in the present study) preferred the violent comic book over the comic book containing little violence. The preference of our participants appears to match the comic book industry's expectations for males.

Trait Hostility. Consistent with previous research assessing hostile attributional bias in adults (Epps \& Kendall, 1995), participants' negative responses to the ambiguous stories increased as their level of trait hostility increased. In fact, trait hostility accounted for more of the variance than did the level of violence in comic books. Thus, hostile attributional bias appears to be influenced more by the personality variable of trait hostility than by short-term exposure to comic book violence. This finding is consistent with previous research showing that personality variables may be stronger predictors of violent thoughts and behaviors than short-term exposure to media violence (Anderson, 1997; Walker \& Morley, 1991; Winkel, Novak \& Hopson, 1987). However, additional research is necessary to see if long-term exposure to comic books will increase their relative influence on hostile attributional bias, as compared to trait hostility.

\section{Primary Analyses}

The results of the present study offer support for the contention that violent comic books influence the perception of ambiguous provocation situations. As expected, when asked about the intent of the harmdoer, male participants reading the very violent comic book responded significantly more negatively than male participants reading the mildly violent comic book. Thus, violent comic books appear to lead to a short-term hostile attributional bias in males. However, no hostile attributional bias was evident for females. These findings are consistent with Crick's (1995) finding that in response to ambiguous provocation stories, aggressive boys responded more negatively than nonaggressive boys. However, Crick did not find a significant difference between aggressive and nonaggressive 
girls. One possible explanation for this gender difference may be related to the nature of the dependent variable. In both the present study and in Crick's study, the dependent variable assessed physical aggression. For example, in the present study, the protagonist of the story was either doused with milk, tripped into a puddle, or hit in the back with a ball. Females, however, typically engage in hostility or so-called relational aggression (Crick, 1995). That is, female aggression is typically designed to hurt the social status of another person. Thus, it may be that the type of aggression used in assessments of hostile attributional bias influence responding. Future research needs to assess the influence of violent media on relational aggression and hostility.

Based on the contention that a hostile attributional bias influences retaliatory aggression, participants reading the Curse of the Spawn were expected to suggest more retaliation and expect more punishment than participants reading the Archie \& Friends. This hypothesis was supported. Participants reading the very violent comic book recommended more retaliation than participants reading the mildly violent comic book. These findings are consistent with research showing a link between aggressive themes in comic books and aggressive feelings (Brand, 1969), as well as research showing an increased rate of aggression following violent video game play (Funk, 1993). Interestingly, no gender differences were found for this question. Males and females reported equal levels of retaliation. The relatively small sample of males limited the power of our analyses. Thus, it may be that in a larger sample, gender differences in retaliation would appear. However, it is also possible that for females and males, violent comic books influence retaliation in a similar manner. Comic book violence may impact different aspects of social cognition (e.g., intent and emotion attributions) differently for males and females. This is an area for future research.

The hypothesis that participants reading the violent comic book would ascribe a negative emotional state to the harmdoer was only partially supported. Males reading the very violent comic book were significantly more likely than males reading the mildly violent comic book to ascribe a negative emotional state to the harmdoer. However, no significant differences between the experimental groups were evident for females. Once again, this gender difference may be related to a dependent variable that utilized physically aggressive instead of relationally aggressive scenarios.

For female participants, violent comic books appeared to have less of an effect on the processing of social information than for males. This finding demonstrates that the impact of this form of violent media is multifaceted. Males and females appear to be influenced similarly in regard to retaliation, but differentially in regard to intent and emotion attributions. In addition to the 
contention that the dependent variable, which assessed physical aggression, influenced responding, it is also possible that females did not become engaged in the story found within the very violent comic book. If an individual does not like the comic book or find it is interesting, it's possible that they will not become engaged enough in the story to have its content affect social cognition. In the present study, females may not have become engaged in the graphic and violent comic book. Our results indicated that females liked Curse of the Spawn significantly less than did males and were significantly less interested in the very violent comic book than were males.

Huesmann (1988) contended that in response to experiences with aggressive behavior, including the observation of aggressive acts performed by others, individuals develop aggressive scripts. These scripts contain information regarding the participants and events surrounding the aggressive act, such as the nature of the provocation and subsequent response. Short-term TV violence is thought to trigger already established aggressive scripts and strengthen their pathways. The data from the present study suggest that short-term exposure to comic books may also lead to the development of aggressive scripts. Very violent comic books influenced the perception of ambiguous provocation situations (including the nature of provocation and subsequent response), after removing the influence of trait hostility. However, additional research is necessary to determine how long after reading violent comic books the negative perception of social situations lasts. It may be reasonable to conclude that the effects of these aggressive scripts may last longer or perhaps be stronger in individuals who are dispositionally hostile than in those who are not.

In conclusion, the results of the present study suggest that the processing of ambiguous provocation situations are affected by both personality-based variables, such as hostility, and environmental factors, such as media influences (see Snyder \& Ickes, 1985 for a review of Person x Situation interactions). Research has shown that finding effects of media on adults is more difficult than finding effects in children (Dubow \& Miller, 1996). Given the fact that the target audience for comic books is primarily 10- to 14-year-old boys, the present study's finding that violent comic books influence adult males more than females suggests that a similar assessment in children and early adolescents is warranted. Violent comic books may have the biggest negative impact on those that read comic books the most.

\section{REFERENCES}

Anderson, C. A. (1997). Effects of violent movies and trait hostility on hostile feelings and aggressive thoughts. Aggressive Behavior, 23, 161-178. 
Antonucci, M. (1998). Holy sales slump! Comic-book industry hit with a slowdown. Knight-Ridder Tribune Business News [Online]. Available: DIALOG File 20: World Reporter.

Berkowitz, L. (1984). Some effects of thoughts on anti-and prosocial influences of media events: A cognitive neoassociationistic analysis. Psychological Bulletin, 95, 410-427.

Brand, J. (1969). The effect of highly aggressive content in comic books on seventh grade children. Graduate Research in Education and Related Disciplines, 5, 46-61.

Brody, L. R. (1993). Gender differences in emotional development: A review of theories and research. Journal of Personality, 53(2), 102-149.

Buss, A. H., \& Durkee, A. (1957). An inventory for assessing different kinds of hostility. Journal of Consulting Psychology, 21(4), 343-349.

Cesarone, B. (1998). Video games: Research, ratings, recommendations. Eric Digest (EDO-PS-98-11).

Crick, N. R., (1995). Relational aggression: The role of intent attributions, feelings of distress, and provocation type. Development and Psychopathology, 7, 313-322.

DeCesare, A., \& Goldberg, S. (1998). Archie \& friends. Archie Comics (Issues $29 \& 471)$.

Diamond Comic Distributors. (1999). Available: http://www.diamondcomic.com.

Dodge, K. A. (1980). Social cognition and children's aggressive behavior. Child Development, 51, 162-170.

Dodge, K. A., \& Frame, C. L. (1982). Social cognitive biases and deficits in aggressive boys. Child Development, 53, 620-625.

Dubow, E. F., \& Miller, L. S. (1996). Television violence viewing and aggressive behavior. In T. M. MacBeth (Ed.), Tuning in to young viewers: Social science perspectives on television (pp.117-148). London: Sage.

Epps, J., \& Kendall, P. C. (1995). Hostile attributional bias in adults. Cognitive Therapy and Research, 19(2), 159-178.

Feshbach, S., \& Weiner, B. (1986). Personality. Lexington, MA: Heath.

Frank, L. K. (1939). Projective methods for the study of personality. Journal of Psychology, 8, 343-389.

Funk, J. B. (1993). Reevaluating the impact of violent video games. Clinical Pediatrics, 32, 86-90.

Geen, R. G. (1998). Aggression and antisocial behavior. In D. T. Gilbert, S. T. Fiske, \& G. Lindzey (Eds.), The Handbook of Social Psychology. (4th ed., Vol 2, pp. 317-356). Boston: McGraw-Hill. 
Gillmore, M. R., Morrison, D. M., Richey, C. A., Balassone, M. L., Gutierrez, L., \& Farris, M. (1997). Effects of a skill-based intervention to encourage condom use among high risk heterosexually active adolescents. AIDS Education and Prevention, 9, 22-43.

Gordon, S., \& Conant, R. (1974). Why use comic books to teach about sex? In G. J. Williams \& S. Gordon (Eds.), Clinical child psychology: Current practices and future perspectives (pp. 351-362). New York: Behavioral Publications.

Hirschman, E. C. (1987). Consumer preferences in literature, motion pictures, and television programs. Empirical Studies of the Arts, 5(1), 31-46.

Huesmann, L. R. (1988). An information processing model for the development of aggression. Aggressive Behavior, 14, 13-24.

Janda, L. H. (1998). Psychological testing: Theories and applications. Boston, MA: Allyn \& Bacon.

Kirsh, S. J. (1998). Seeing the world through "Mortal Kombat" colored glasses: Violent video games and the development of a short-term hostile attribution bias. Childhood, 5(2), 177-184.

Knott, P. D. (1970). A further methodological study of the measurement of interpersonal aggression. Psychological Reports, 26(3), 807-809.

Kokaska, C. J. (1984). Disabled superheroes in comic books. Rehabilitation Literature, 45, 286-288.

McCloud, S. (1993). Understanding comics. Northampton, MA: Kitchen Sink Press.

McElroy, A. (1998). Curse of the Spawn. Image Comics. (Issues 12 and 18).

Parke, R. D., \& Slaby, R. G. (1983). The development of aggression. In P. H. Mussen (Series Ed.) \& M. Hetherington (Vol. Ed.), Handbook of child psychology: Vol. 4. Socialization, personality, and social development (4th ed., pp. 547-642). New York: Wiley.

Petzel, T. P., \& Michaels, E. J. (1973). Perception of violence as a function of levels of hostility. Journal of Consulting and Clinical Psychology, 41, 35-36.

Potenza, M., Verhoeff, P., \& Weiss, E. (1996). Comic books and development. Journal of the American Academy of Child and Adolescent Psychiatry, 35, 1573-1574.

Savage, W. W. (1990). Comic books and America, 1945-1954. Norman, OK: University of Oklahoma Press.

Slaby, R. G., \& Guerra, N. G. (1988). Cognitive mediators of aggression in adolescent offenders: 1. Assessment. Developmental Psychology, 24, $580-588$. 
Snyder, M., \& Ickes, W. (1985). Personality and social behavior. In G. Lindzey \& E. Aronson (Eds.), The handbook of social psychology, Vol. 2 (pp. 883-947). NY: Random House.

Steinberg, M. S., \& Dodge, K. A. (1983). Attributional bias in aggressive adolescent boys and girls. Journal of Social and Clinical Psychology, 1(4), 312-321

Walker, K. B. \& Morley, D. D. (1991). Attitudes and parental factors as intervening variables in the television violence-aggression relation. Communication Research Reports, 8, 41-47.

Wertham, F. (1954). Seduction of the innocent. New York: Holt, Rinehart \& Winston.

Winkel, M., Novak, D. M., \& Hopson, H. (1987). Personality factors, subject gender, and the effects of aggressive video games on aggression in adolescents. Journal of Research in Personality, 21(2), 211-223. 